\title{
Derangements of Thyroid Hormones and Hypothalmo-Pitutary-Thyroid (HPT) Axis in Preterm Neonates
}

\author{
Dr. Sunita Yadav ${ }^{1}$, Dr. Rupita Kulshrestha ${ }^{2 *}$, Dr. Manish Raj Kulshrestha ${ }^{3}$, Dr. Rakesh Kumar Kalra ${ }^{4}$ \\ ${ }^{1}$ Consultant Pathologist, Midland Healthcare and Research Centre, Lucknow Uttar Pradesh India \\ ${ }^{2}$ Assistant Professor, Department of Obstetrics and Gynecology Mayo Institute of Medical Sciences, Barabanki Uttar Pradesh India \\ ${ }^{3}$ Associate Professor Department of Biochemistry, Dr. Ram Manohar Lohia Institute of Medical Sciences, Lucknow Uttar Pradesh India \\ ${ }^{4}$ Associate Professor, Department of Pediatrics, N. C. Medical College, Israna Panipat, Haryana India
}

\begin{abstract}
DOI: $10.36348 /$ sjpm.2020.v05i04.001 $\quad$ | Received: 27.03.2020 | Accepted: 03.04.2020 | Published: 07.04.2020
*Corresponding author: Dr. Rupita Kulshrestha
\end{abstract}

Abstract

Introduction: Preterm neonates have deranged thyroid hormones levels often characterized by low $\mathrm{T}_{3} / \mathrm{FT}_{3}$ and often low to normal $\mathrm{T}_{4} / \mathrm{FT}_{4}$ and TSH levels. Thus, it may be essential to find the pattern of thyroid hormones levels in preterm in comparison to term neonates, the status of HPT axis in preterms and occurrence of Transient Hypothyroxinemia of Prematurity (THOP) in this part of globe, since serum $\mathrm{FT}_{3}$ and $\mathrm{FT}_{4}$ levels are correlated with TSH levels after establishment of HPT axis. We have focussed on these hormones in our study. Methods: This prospective observational study was conducted at a tertiary care centre in Northern India including 100 neonates in the study group (33 preterm and 67 term neonates as per gestational age). $\mathrm{FT}_{3}, \mathrm{FT}_{4}$ and $\mathrm{TSH}$ were estimated by electrochemiluminescence immunoassay (ECLIA) using diagnostic kits from Roche Diagnostics. The history of maternal illness, gestational age and birth weight of each neonate was recorded. Results: All the three hormones i.e. $\mathrm{FT}_{3}, \mathrm{FT}_{4}$ and TSH were significantly lower in preterm in comparison to term neonates. In term neonates $\mathrm{FT}_{3}$ was significantly correlated to both $\mathrm{FT}_{4}(\mathrm{r}=0.453 ; \mathrm{p}=0.00)$ and TSH ( $\mathrm{r}=0.299$; $\mathrm{p}=0.014)$ while no such correlation was found in preterm neonates. Discussion: Both sick euthyroid (low $\mathrm{T}_{3}$ syndrome) and transient hypothyroxinemia of premature infants (THOP) are noticed in pereterm neonates. The causes of low $\mathrm{T}_{3}$ syndrome may include hypoxemia, acidosis, infections, hypoglycemia, hypocalcemia, malnutrition, transient secondary/tertiary hypothyroidism, transient primary hypothyroidism and permanent primary hypothyroidism while THOP may be caused by iodine deficiency, maternal thyrotropin receptor blocking antibodies, maternal intake of antithyroid drugs, maternal or neonatal iodine exposure, loss of function mutations and hepatic haemangioma(20), maternal hyperthyroidism, prematurity and drugs. Since it may lead to undesirable neurodevelopmental outcome, thyroid hormones supplementation in preterms should be cautiously studied in larger sample size. Also, these factors must be considered while screening for congenital hypothyroidism.

Keywords: Triiodothyronine $\left(\mathrm{T}_{3}\right)$, Tretraiodothyronine $\left(\mathrm{T}_{4}\right)$, thyroid stimulating hormone (TSH), Transient Hypothyroxinemia of prematurity (THOP), Hypothalamo-Pituitary-Thyroid axis (HPT) axis.

Copyright @ 2020: This is an open-access article distributed under the terms of the Creative Commons Attribution license which permits unrestricted use, distribution, and reproduction in any medium for non-commercial use (NonCommercial, or CC-BY-NC) provided the original author and sources are credited.

\section{INTRODUCTION}

The progressive major advances during the past few decades in the management of premature neonates has caused significant reduction in their mortality and more than $50 \%$ of neonates less than 24 weeks gestation age (GA) now survive, increasing the numbers of VLBW (VLBW, $<1500$ grams and $<30$ weeks GA) neonates in nursery intensive care units[1].

Thyroid gland function develops and matures during fetal life, with production of serum thyroxine $\left(\mathrm{T}_{4}\right)$ beginning around 12 week's gestation and increasing to term [2]. As compared to term neonates, preterm neonates experience a fall in serum $\mathrm{T}_{4}$ and $\mathrm{T}_{3}$ levels to below birth levels in first week of life. This fall appears to be the result of many factors, like nutritional challenges and decreased hepatic Thyroid Binding Globulin (TBG) production, immaturity of hypothalamic-pituitary-thyroid (HPT) axis, and immaturity of the thyroid tissues itself, and increased tissue utilization of $\mathrm{T}_{4}$. These changes are further influenced by complications of prematurity, such as respiratory distress syndrome (RDS), sepsis, and intraventricular hemorrhages etc. which result in nonthyroidal illness-like changes [3].

Thyroid hormones play a critical role in central nervous system development and function, and thyroid 
system immaturities as well as morbidity-related thyroid dysfunction (the nonthyroidal illness syndrome) contribute to the transient hypothyroxinemia of premature infants (THOP)[4,5]. Transient hypothyroxinemia is the commonest thyroid dysfunction in preterm infants and is characterized by temporary postnatal reductions in whole blood levels of $\mathrm{T}_{4}$ [6] or sera free $\mathrm{T}_{4}\left(\mathrm{FT}_{4}\right)$ [7] but with normal levels of TSH $[6,8]$. Transient hypothyroxinemia was previously thought to be without clinical significance $[6,8]$, but recent studies have found adverse associations between THOP and neurodevelopment [9-12], and low postnatal levels of $\mathrm{T}_{3}$ and neurodevelopment [13].

Thus, it may be essential to characterize how thyroid hormones levels are different in preterms in comaprison to term neonates, the status of HPT axis in preterms and occurrence of THOP in this part of globe. Since serum $\mathrm{FT}_{3}$ and $\mathrm{FT}_{4}$ levels are correlated with TSH levels after establishment of HPT axis. We have focussed on these hormones in our study.

\section{MATERIALS AND METHODS}

This prospective observational study was conducted at a tertiary care centre in northern India including 100 neonates in the study as 21 with very low birth weight (VLBW; <1500gms), 23 with low birth weight (LBW; <2500 gms) and 56 with normal birth weight (>2500 gms).

After taking an informed consent from the parent/ guardian, $2 \mathrm{ml}$ of venous blood sample was collected from all neonates after 72 hours of life in a sterile vacutainer.FT $4, \mathrm{FT}_{3}$ and $\mathrm{TSH}$ were estimated by electrochemiluminescence immunoassay (ECLIA) using diagnostic kits from Roche Diagnostics. The neonates were categorized in two groups based on their gestational age. Those born $\geq 37$ weeks were categorized as term neonates while those $\leq 37$ weeks as preterm neonates. The history of maternal illness, gestational age and birth weight of each neonate was recorded. As per gestational age (GA) there were 33 preterm and 67 term neonates in the study group.

\section{RESULTS}

We observed 33 preterm and 67 term neonates in our study group. Out of 33 preterm, there were 19 males and 14 females while out of the 67 term neonates, there were 41 males and 26 females.

On categorization of neonates on the basis of $\mathrm{GA}$, it was found that all the three hormones i.e. $\mathrm{FT}_{3}$, $\mathrm{FT}_{4}$ and TSH was significantly lower in preterm in comparison to term neonates (Table 1).

The $\mathrm{FT}_{3}$ in very low birth weight (VLBW) neonates was significantly lower than low birth weight (LBW) babies $(\mathrm{p}=0.038)$ and normal birth weight babies $(\mathrm{p}<0.001) . \mathrm{FT}_{4}$ and TSH were also being lowest in VLBW and highest in neonates with normal birth weight (BW) but none of these differences were statistically significant (Table 2).

In term neonates $\mathrm{FT}_{3}$ was significantly correlated to both $\mathrm{FT}_{4}(\mathrm{r}=0.453 ; \mathrm{p}=0.00)$ and $\mathrm{TSH}$ $(\mathrm{r}=0.299 ; \mathrm{p}=0.014)$ while no such correlation was found in preterm neonates suggesting better development of HPT axis in term neonates than in preterm neonates.

Table-1: A comparison of $\mathrm{FT}_{3}, \mathrm{FT}_{4}$ and $\mathrm{TSH}$ among preterm and term neonates

\begin{tabular}{|c|c|c|c|}
\hline & $\begin{array}{c}\text { Preterm neonates } \\
(\mathrm{n}=33)\end{array}$ & $\begin{array}{c}\text { Term neonates } \\
(n=67)\end{array}$ & p Value \\
\hline FT $_{3}(\mathrm{pg} / \mathrm{ml})($ Mean \pm S.D. $)$ & $3.44 \pm 1.06$ & $4.47 \pm 1.44$ & $<0.001 *$ \\
\hline $\mathrm{FT}_{4}(\mathrm{ng} / \mathrm{dl})(\mathrm{Mean} \pm$ S.D. $)$ & $21.08 \pm 5.44$ & $25.66 \pm 6.7$ & 0.049 \\
\hline TSH $(\mu \mathrm{IU} / \mathrm{ml})($ Mean+S.D. $)$ & $3.31 \pm 2.14$ & $6.10 \pm 3.37$ & 0.042 \\
\hline
\end{tabular}

$* P$ value $<0.05$ i.e.the $\mathrm{FT}_{3}$ of was significantly lower in preterm neonates in comparison to term neonates

Table-2: A comparison of $\mathrm{FT}_{3}, \mathrm{FT}_{4}$ and TSH among VLBW, LBW and normal birth weight neonates

\begin{tabular}{|c|c|c|c|c|}
\hline & $\mathbf{n}$ & $\begin{array}{c}\text { VLBW } \\
(\mathbf{n = 2 1})\end{array}$ & $\begin{array}{c}\text { LBW } \\
(\mathbf{n = 2 3})\end{array}$ & $\begin{array}{c}\text { Normal BW } \\
(\mathbf{n = 5 6})\end{array}$ \\
\hline FT $_{\mathbf{3}}$ (Mean \pm S.D.) & 21 & $3.13 \pm 0.99 *$ & $4.11 \pm 1.09$ & $4.51 \pm 1.48$ \\
\hline FT $_{\mathbf{4}}$ (Mean+S.D.) & 23 & $19.15 \pm 3.77$ & $22.76 \pm 5.29$ & $24.20 \pm 7.10$ \\
\hline TSH(Mean+S.D.) & 56 & $3.16 \pm 2.35$ & $4.66 \pm 2.96$ & $4.96 \pm 3.45$ \\
\hline
\end{tabular}

$* P$ value $<0.05$ i.e.the $\mathrm{FT}_{3}$ of was significantly lower in $\mathrm{VLBW}$ neonates in comparison to $L B W$ neonates and the normal $B W$ neonates

\section{DISCUSSION}

The $\mathrm{FT}_{3}, \mathrm{FT}_{4}$ and $\mathrm{TSH}$ levels in preterm were significantly low in comparison to term neonates in our study population similar to findings by Dilli $\mathrm{D}$ et al. [14] Zhu L et al. defined reference intervals of $\mathrm{FT}_{3}, \mathrm{FT}_{4}$ and TSH for preterm infants according to their gestational age but they admit lack of consensus [15].
Low $\mathrm{T}_{3}$ levels in conjunction with low or normal free $\mathrm{T}_{4}$ and TSH levels are linked to nonthyroidal disease (euthyroid sick syndrome) [16]. In prematurity, several factors can inhibit the conversion of peripheral $\mathrm{T}_{4}$ to $\mathrm{T}_{3}$, including hypoxemia, acidosis, infections, hypoglycemia, hypocalcemia and malnutrition and also some rare conditions like transient secondary/tertiary hypothyroidism, transient primary 
hypothyroidism and permanent primary hypothyroidism [17].

Only $\mathrm{FT}_{3}$ was found significantly low in VLBW neonates in comparison to LBW and normal birth weight counterparts. $\mathrm{FT}_{4}$ and $\mathrm{TSH}$ were also lower though statistically indifferent.

All VLBW neonates have relatively low, gestational age-dependent, thyroxine-binding globulin (TBG) concentrations associated with variably low total thyroxine $\left(\mathrm{T}_{4}\right)$ concentrations. These neonates also have a high prevalence $(30 \%-60 \%)$ of nonthyroidal illnesses which influence thyroid function, including total and free iodothyronine concentrations. As a result, VLBW neonates manifest a high prevalence of transient primary hypothyroidism $(0.41 \%)$ and transient hypothalamic- hypothyroidism (thyrotropin /TSH deficiency) $(5 \%-10 \%)[18]$.

The TSH levels though decreased, gets normalized over a few weeks. Hence, it is known as Transient Hypothyroxinemia of Preterms (THOP) or Transient congenital hypothyroidism $[19,20]$. It may be caused by iodine deficiency, maternal thyrotropin receptor blocking antibodies, maternal intake of antithyroid drugs, maternal or neonatal iodine exposure, loss of function mutations and hepatic haemangioma [20] or factors those that affect the pituitary-like untreated maternal hyperthyroidism, prematurity and drugs [21].

Preterm babies are remarkably susceptible to the effects of iodine deficiency, due to decreased in utero thyroidal iodine stores, immature HPT axis for $\mathrm{T}_{4}$ production, and decreased ability to convert $T_{4}$ to $T_{3}$. Deficiency of other elements, selenium and iron may effect neurologic development and thyroidal response to iodine supplementation [22].

The maternal exposure of certain drugs like propylthiouracil or methimazole (antithyroid) or iodine antiseptics/ excessive iodine ingestion/amniofetography with iodine containing contrast may also induce transient congenital hypothyroidism [20, 23, 24] Exposure of preterms to high amounts of iodine may cause hypothyroidism due to Wolff-Chaikoff effect [25, 26].

Though the foetal HPT axis begins to function after the first trimester, its maturation is not completed till at term as evident from our data also where we found that only in term neonates $\mathrm{FT}_{3}$ was significantly correlated to both $\mathrm{FT}_{4}(\mathrm{r}=0.453 ; \mathrm{p}=0.00)$ and $\mathrm{TSH}$ $(r=0.299 ; p=0.014)$. However, the exact gestational age at which this axis is developed could not be determined due to scarcity of data at individual gestational ages.

\section{CONCLUSION}

Our study concludes that maturity of HPT axis is better in term neonates than in preterm neonates. Preterm neonates also are prone to develop sick euthyroid syndrome and THOP. The incidence of THOP increases reciprocally with gestational age [27] as observed in our study also. Hypothyroxinemia without thyrotropin elevation does not require treatment, and some potential risks of levothyroxine supplementation have been reported. Although most thyroid dysfunctions are transient, careful follow-up after discontinuation of levothyroxine is considered so as to avoid missing persistent hypothyroidism [20].

\section{REFERENCES}

1. Fisher, D. A. (2007). Thyroid function and dysfunction in premature infants. Pediatric endocrinology reviews: PER, 4(4), 317-328.

2. Petriczko, E., \& Walczak, M. (2013, December). Permanent and transient congenital hypothyroidism in full-term and preterm born infants. In Thyroid research (Vol. 6, No. 2, p. A47). BioMed Central.

3. LaFRANCHI, S. T. E. P. H. E. N. (1999). Thyroid function in the preterm infant. Thyroid, 9(1), 71-78.

4. Fisher, D. A. (2008, December). Thyroid system immaturities in very low birth weight premature infants. In Seminars in perinatology (Vol. 32, No. 6, pp. 387-397). WB Saunders.

5. Williams, F. L., Visser, T. J., \& Hume, R. (2006). Transient hypothyroxinaemia in preterm infants. Early human development, 82(12), $797-$ 802.

6. Frank, J. E., Faix, J. E., Hermos, R. J., Mullaney, D. M., Rojan, D. A., Mitchell, M. L., \& Klein, R. Z. (1996). Thyroid function in very low birth weight infants: effects on neonatal hypothyroidism screening. The Journal of pediatrics, 128(4), 548554.

7. Rooman, R. P., Du Caju, M. V. L., De Beeck, L. O., Docx, M., Van Reempts, P., \& Van Acker, K. J. (1996). Low thyroxinaemia occurs in the majority of very preterm newborns. European journal of pediatrics, 155(3), 211-215.

8. Fisher, D. A., Klein, A. H., \& Hadeed, A. (1981). Normal and abnormal thyroid function in premature infants: the low T3 syndrome. In Proceedings of the Serono Symposium (Vol. 40, pp. 225-231).

9. Reuss, M. L., Paneth, N., Pinto-Martin, J. A., Lorenz, J. M., \& Susser, M. (1996). The relation of transient hypothyroxinemia in preterm infants to neurologic development at two years of age. New England Journal of Medicine, 334(13), 821-827.

10. Meijer, W. J., Verloove-Vanhorick, S. P., Brand, R., \& Van den Brande, J. L. (1992). Transient hypothyroxinaemia associated with developmental delay in very preterm infants. Archives of disease in childhood, 67(7), 944-947.

11. Den Ouden, A. L., Kok, J. H., Verkerk, P. H., Brand, R., \& Verloove-Vanhorick, S. P. (1996). 
The relation between neonatal thyroxine levels and neurodevelopmental outcome at age 5 and 9 years in a national cohort of very preterm and/or very low birth weight infants. Pediatric research, 39(1), 142-145.

12. Simic, N., Asztalos, E. V., \& Rovet, J. (2009). Impact of neonatal thyroid hormone insufficiency and medical morbidity on infant neurodevelopment and attention following preterm birth. Thyroid, 19(4), 395-401.

13. Lucas, A., Rennie, J., Baker, B. A., \& Morley, R. (1988). Low plasma triiodothyronine concentrations and outcome in preterm infants. Archives of disease in childhood, 63(10), 1201-1206.

14. Dilli, D., Oğuz, Ş. S., Andıran, N., Dilmen, U., \& Büyükkağnıc1, Ü. (2010). Serum thyroid hormone levels in preterm infants born before 33 weeks of gestation and association of transient hypothyroxinemia with postnatal characteristics. Journal of Pediatric Endocrinology and Metabolism, 23(9), 899-912.

15. Zhu, L., Zhang, X., He, X., Yang, X., Wang, Y., Wang, C., \& Feng, Z. (2013). Reference intervals for serum thyroid hormones in preterm hospitalized infants1. Journal of Pediatric Endocrinology and Metabolism, 26(5-6), 463-467.

16. Korkmaz, G., Özçetin, M., Çağ, Y., Yükselmiş, U., Öngel, V., \& Iş1k, O. (2018). Thyroid function in healthy and unhealthy preterm newborns. African health sciences, 18(2), 378-383.

17. MacGillivray, M. (2004). Congenital hypothyroidism. In: Pes-covitz OH, Eugster EA (eds). Pediatric endocrinology. Phila- delphia: Lipincott Williams \& Wilkins; 490-507.

18. Fisher, D. A. (1999). Hypothyroxinemia in premature infants: is thyroxine treatment necessary?. Thyroid, 9(7), 715-720.
19. Chung, H. R. (2019). Screening and management of thyroid dysfunction in preterm infants. Annals of pediatric endocrinology \& metabolism, 24(1), 15.

20. Kanike, N., Davis, A., \& Shekhawat, P. S. (2017). Transient hypothyroidism in the newborn: to treat or not to treat. Translational pediatrics, 6(4), 349.

21. Bhavani, N. (2011). Transient congenital hypothyroidism. Indian journal of endocrinology and metabolism, 15(Suppl2), S117.

22. Delange, F., Bürgi, H., Chen, Z. P., \& Dunn, J. T. (2002). World status of monitoring of iodine deficiency disorders control programs. Thyroid, 12(10), 915-924.

23. Connelly, K. J., Boston, B. A., Pearce, E. N., Sesser, D., Snyder, D., Braverman, L. E., ... \& LaFranchi, S. H. (2012). Congenital hypothyroidism caused by excess prenatal maternal iodine ingestion. The Journal of pediatrics, 161(4), 760-762.

24. Rodesch, F., Camus, M., Ermans, A. M., Dodion, J., \& Delange, F. (1976). Adverse effect of amniofetography on fetal thyroid function. American Journal of Obstetrics \& Gynecology, 126(6), 723-726.

25. Linder, N., Davidovitch, N., Reichman, B., Kuint, J., Lubin, D., Meyerovitch, J., \& Sack, J. (1997). Topical iodine-containing antiseptics and subclinical hypothyroidism in preterm infants. The Journal of pediatrics, 131(3), 434-439.

26. Aitken, J., \& Williams, F. L. (2014). A systematic review of thyroid dysfunction in preterm neonates exposed to topical iodine. Archives of Disease in Childhood-Fetal and Neonatal Edition, 99(1), F21F28.

27. Fisher, D. A. (2007). Thyroid function and dysfunction in premature infants. Pediatric endocrinology reviews: PER, 4(4), 317-328. 